One Welfare State for Europe: A Costly Utopia?

by

Thierry Warin

Peter Hennessy

September 2003

MID DLEBURY COLLEGE ECONO MICS D ISCUSSION PAPER NO. 03-25

DEPARTMENT OF ECONOMICS
MIDDLEBURY COLLEGE
MIDDLEBURY, VERMONT 05753

http:/ / www.middlebury.edu/ econ 


\title{
One Welfare State for Europe: A Costly Utopia?
}

\author{
Thierry Warin*\& Peter Hennessy \\ Middlebury College
}

September 2003

\begin{abstract}
This paper addresses the question of the social policy harmonization in the European Union. In adopting a common monetary policy Europe is faced with structural and fiscal concerns, as national growth levels differ. Another possible factor in output shocks are the levels of various social expenditures in the member countries. OECD data on the level of social program expenditures in four EU countries will be compared to fluctuations in GDP growth to identify existing relationships. Significant relationships between independent social expenditure policy and GDP growth shocks portends structural harmonization as an improvement if Europe is to take full advantage of the common market. However, the effects of expenditure levels may be easier to identify and predict than the dynamic effects of policy change. As the effects of future policy changes are more difficult to ascertain, harmonization may not consistently appear to be a Pareto-optimum solution to asymmetric shocks.
\end{abstract}

Keywords: Europe, welfare state, coordination, integration. JEL Classification: D6, H77, I18, I38.

${ }^{*}$ Dept of Economics, Middlebury College, Middlebury, Vermont, 05753, USA, email: twarin@middlebury.edu 


\section{Introduction}

The Lisbon Labor and Social Affairs Councils consolidated a process of transformation in European policy style which began in 1992 with recommendations on social protection "convergence." Policy innovation in favor of a social Europe occurred in two main areas: gender, with a series of initiatives "mainstreaming" gender equality across a wide array of EU programs; and employment, with the "Luxembourg process" launched in 1997 seeking a coordination of national policies (Rodhes 2000). In July 1999, the Commission proposed a "concerted strategy for modernizing social protection". And under the Finnish presidency in 1999 a group of officials was asked to take the process forward. That group's first major report (May 2000) was submitted by Coreper and the Council to the European Council meeting held in Feira, Portugal, on 19 and 20 June, and its conclusions now underpin official EU policy.

The Portuguese presidency of the European Union (EU) in 2000 was the first one to put ahead on the European agenda the discussion on "Social Europe". Both the ethical layer and the economic one have been considered by the Portuguese presidency. Two key aspects can be emphasized. On the one hand, there has been a quest for a new synthesis in EU social policy, reconciling flexibility and security in labor markets, and solidarity and sustainability in broader welfare programs. The special meeting of the European Council in Lisbon on 23 and 24 March underlined the need to create an "active welfare state" via a "positive strategy which combines competitiveness with social cohesion" (Rodhes 2000). The Commission's Broad Economic Policy Guidelines published shortly before the Lisbon Summit presents a clear recipe for reform combining at once the ethical dimensions with the economic one: "reducing the tax burden on low-wage labor, encouraging real wages to increase in line with labor productivity, facilitating access to training, reforming tax and benefit systems to ensure appropriate incentives and rewards for participation in active working life and negotiating a modernization of labor markets including flexible working hours and a review of tight job protection legislation and high severance payments."

On the other hand, there has also been a search for a middle path between EU intervention via directives and the alternative of leaving policy instruments in the hands of the member states, thereby renouncing broader social policy ambitions. The "open method of coordination", as outlined by the Portuguese Presidency, is composed of four elements (Mosher 2000): 1) 
fixed guidelines set for the Union with short, medium, and long term goals; 2) quantitative and qualitative indicators and benchmarks; 3) European guidelines translated into national and regional policies and targets; and 4) periodic monitoring, evaluation, and peer review, organized as a mutual learning process (Portuguese Presidency, 2000).

Thus, previously considered by EU policy makers, the next question in the economic literature is the organization of the welfare state. The logic is that an integrated market may require individual states to relinquish some control of their welfare policies. Indeed, the issues surrounding the reform of social expenditures are relevant for two reasons. First, asymmetric economic shocks may be generated by differences in social expenditures. Second, with integration into the Economic and Monetary Union (EMU) the individual countries have come under pressure to limit public spending in order to keep public deficits within the boundaries of the SGP. This constraint will limit the ability to have an individual fiscal response during an asymmetric shock. A country has to consider structural reform to increase its ability to respond to shocks: a more efficient welfare state would leave more room for a fiscal response to shocks.

This paper seeks to answer the question about the relevancy of the convergence of the European welfare states. The integration of different welfare states thus requires attention as the economic ramifications of expenditure convergence are relevant. In our study, one way to analyze the welfare state is to extrapolate measurement from social expenditure data.

\section{Review of the literature}

The definition of the welfare state is broader in Europe than in any other part of the world, and there is no doubt that the expenditures associated with this welfare state definition impact the structure of the states themselves. Nevertheless, while all countries in Europe have advanced welfare states, they are structured differently and require different amounts of funding. These differences may be one of the causes of divergent GDP growth rates in an otherwise more-than-ever unified Europe. Hence on the structural side questions are now arising.

Johnson (Johnson 1968) dealt with the question of the application of economic theory to social issues. The definition of the welfare state that we are going to retain considers two components, one fiscal and one structural. 
The former deals with social expenditures. In the latter welfare regulations form the basis of welfare policy.

\subsection{Welfare state as the next step}

Changes in European policies due to the belonging to the EMU could contribute to natural convergence between countries in public expenditures (Hitiris and Nixon 2001). Still, some in the literature indicate that these differences are important enough so as to necessitate harmonization to speed up economic integration (Hitiris 1997).

The construction of the European Union is centered on monetary policy, with control of fiscal policy left to the individual countries. An uncoordinated fiscal policy leaves individual countries with more independence, but will undermine monetary coordination if there are no limitations to fiscal policy (Delors 1989). The SGP is a form of policy coordination designed to deal with problems associated with a fiscally decentralized Europe and forestall deleterious individual fiscal policy and limit free riding. Depending on the organization of the welfare state, one-way migration traffic may occur in Europe, from states with poorly organized social systems to well-organized welfare states (Holmlund and Kolm 2000). Different welfare structures will cause migrations toward beneficial systems.

\subsection{Welfare State and Competitiveness}

Alesina and Perotti (Alesina and Perroti 1997) examine the impact of the composition of government spending on competitiveness. Distinguishing between spending funded by reduced government spending and spending funded by an increase in taxes yields different outcomes for the economy. As competitiveness is affected by how the welfare state is funded, considerations arise for harmonization. The range of harmonization possibilities includes measures such as common fiscal budgets; new free-riding possibilities present themselves when a collective budget and individual taxation policy are allowed.

Perotti (Perotti 1996) demonstrates that the composition of the welfare state matters, which is relevant to considerations of fiscal policy consolidation. Cutting government spending creates a long-term impact on a budget, whereas measures such as tax increases and capital spending cuts have effects that are shorter-lived. Both GDP growth and competitiveness will be 
impacted by the structure of the welfare-distribution mechanism. The relationship between social expenditure and GDP growth becomes important with the consideration of harmonization. Effective limitations of government spending, while promoting growth, can be achieved more readily under certain conditions. Therefore, combining various welfare states and various welfare state mechanisms becomes political and economic. When these different approaches center around social expenditure it becomes necessary to study the nature of such expenditures and their relationship to the welfare state.

\subsection{The Welfare State and Europe}

The Portuguese EU presidency has put in place a new European architecture for social policy, something that could one day be considered Europe's "Maastricht" for the welfare state. The welfare state is a notion well-covered in the economic literature as well as the European economic integration, but the combination of the two is still brand new.

A major reason to study the welfare state harmonization or coordination comes from the costs of a non-converging Europe. Indeed, it seems important to question whether regional asymmetric shocks were also related to different levels of spending in the welfare state programs (for instance, health care) through the EU countries. As the EU moves toward economic integration levels of income convergence will accelerate. The convergence of incomedependent variables, such as health care expenditure, will also quicken. The possibility that health care expenditures in the EU are currently approaching common levels despite the lack of harmonization policies so far signals the benefit of considering such policies for the future (Hitiris and Nixon 2001).

Members of the EU are under pressure to curtail spending to stay within the bounds of the Stability and Growth Pact, and some of this pressure will be placed on health care budgets, possibly leading toward a common level.

\section{Specifications of the Model}

The level of various public expenditures and the structure of programs designed to uphold welfare where the free market might not have an interest is determined on a country level. The European Commission believes that Europe could gain from a common monetary policy, with member countries 
acting as a group. Assessing the impact of structural differences on the economic health of the EMU may provide further gains and guide future policy formation.

\subsection{Purpose of the Model}

There are many different ways of measuring the welfare state (Slesnick 1998) and this paper will follow Barr's methodology (Barr 1992). This paper will use social expenditure data to reflect the composition of social welfare programs in European states. The data is from the OECD Social Expenditure Database (the 'SOCX' database), a data set covering social expenditures both public and private in OECD countries from 1980-1998. The model examines changes in GDP growth and fluctuation in social expenditures, to provide a meaningful foundation for an assessment of structural harmonization in Europe.

\subsection{Manipulation of the database}

For this model, we have reformulated ${ }^{1}$ the database categories for consistency and relevancy of the data set. Four new categories are designed ${ }^{2}$ :

- 'Total social expenditure' is simply the sum of all programs listed in the SOCX database covering all public expenditure defined by the OECD as providing for public welfare. To eliminate GDP effects, 'Total social expenditure' is divided by the GDP for each year.

- 'Old Age Oriented' Variable, 'O' The program 'Services for the elderly and disabled' was added to 'Old age cash benefits' to create an 'old age oriented' variable.

- 'Family Oriented' Variable, 'F' 'Family cash benefits' and 'Family services' are closely related within the SOCX database, and include public expenditures to support households of more than one person.

\footnotetext{
${ }^{1}$ The reformulated data set includes some unaltered categories of the OECD database, such as 'Unemployment' and 'Old Age Cash Benefits,' but it also includes variables such as the 'Family Oriented' variable reflecting the levels of several programs of similar aim.

${ }^{2}$ When several programs that serve a related purpose are combined in a reformulated variable, the significance of the new variable is in almost all cases greater than the individual significance of component programs.
} 
- 'Disability Oriented' Variable, 'D' The 'Disability oriented' variable is meant to cover benefits awarded to people to compensate for income lost through sickness, injury, or the death of a spouse.

\section{The Model}

The goal of the econometrics is twofold: on the one hand, we measure the structural impacts of national social expenditure on the growth rates. This first step will help in understanding whether an economic policy devoted to the social harmonization is worth or not, ceteris paribus. In other words, the analysis will try to capture any structural impact of the social expenditure from the data. If there is any, the harmonization might be desirable. In fact, it would as long as the implementation of such an economic policy would not generate new costs. In term of percentage of public social expenditure, data do not clearly demonstrate a convergence of unemployment, disability, family and old age programs (see figures 1, 2, 3, and 4). Indeed, the change from a national economy structured by the national social expenditure to a more homogeneous structure could also create negative externalities. Hence, on the other hand, we measure the impact of a policy that would give way to the European harmonization of social expenditure, the so-called "dynamic effect" model presented below. For econometric consistency, we also verified that different levels of social expenditures from year to year contribute to fluctuations in GDP.

What is important in this part of the analysis is not the level of the expenditure, but the level of the difference between countries. Policy considerations will ultimately be founded on what can be determined about international growth asymmetries; using the differences in amount of expenditure to explain output fluctuations will begin this process. More complete answers about social expenditure's impact on GDP derive from policy comparison. To this end policy choices in individual countries are examined to see if these choices impact GDP growth. Policy choices are represented by the change in the percentage of social expenditure for each variable and country. This procedure, incorporating welfare program structure and underlying policy, is an initial step toward determining precisely why output and growth asymmetries exist. We will present the best results of the analysis based on four core countries - France, Italy, Germany, and Spain. We retain the strongest 


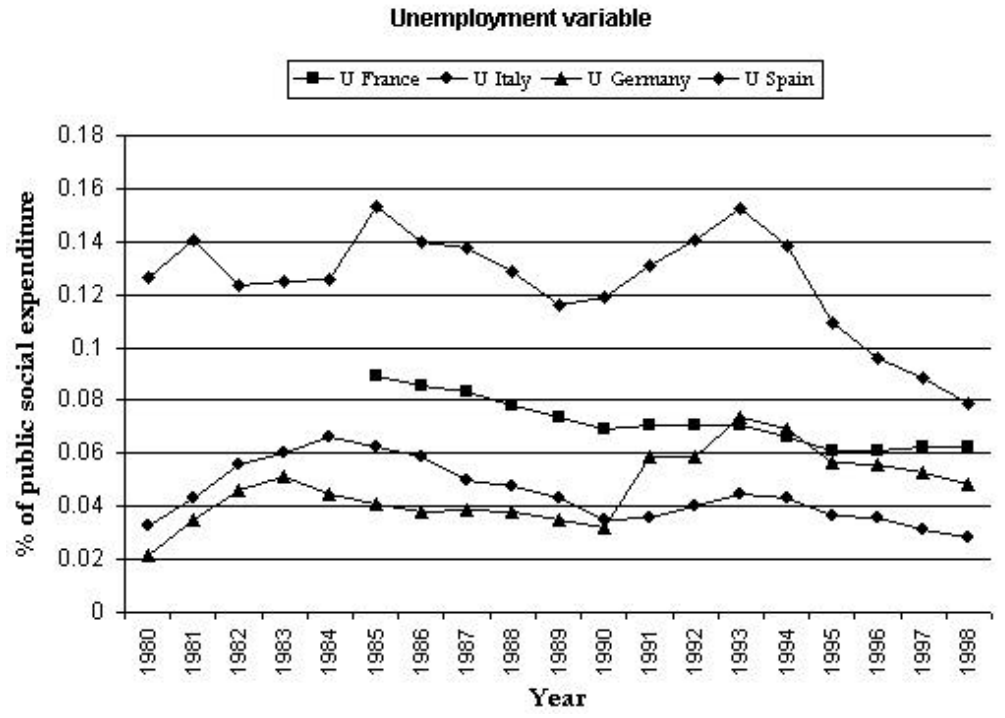

Figure 1: Percentage of socex in unemployment programs

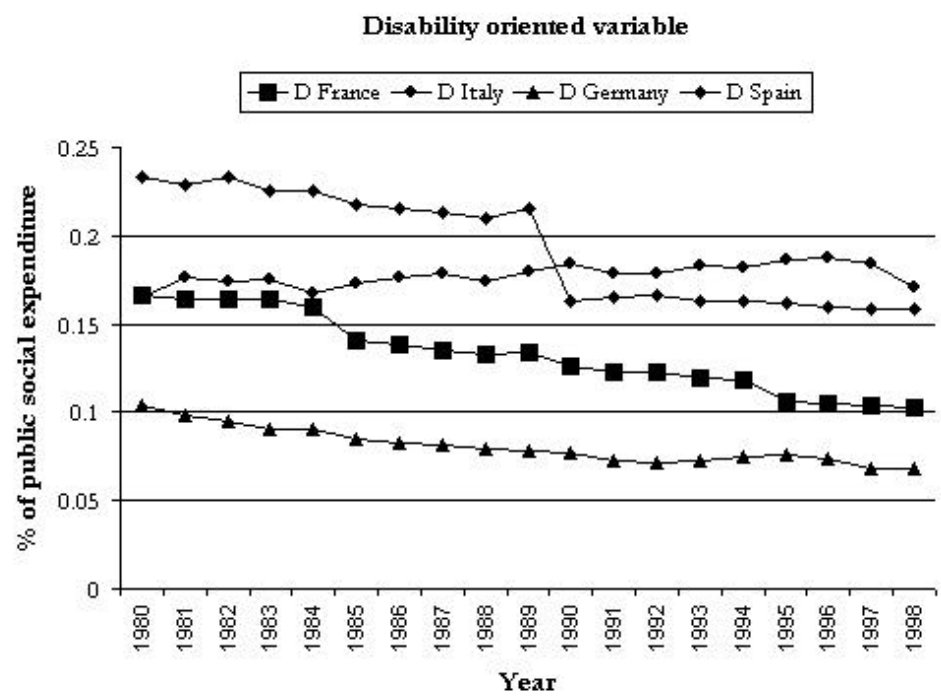

Figure 2: Percentage of socex in disability programs 


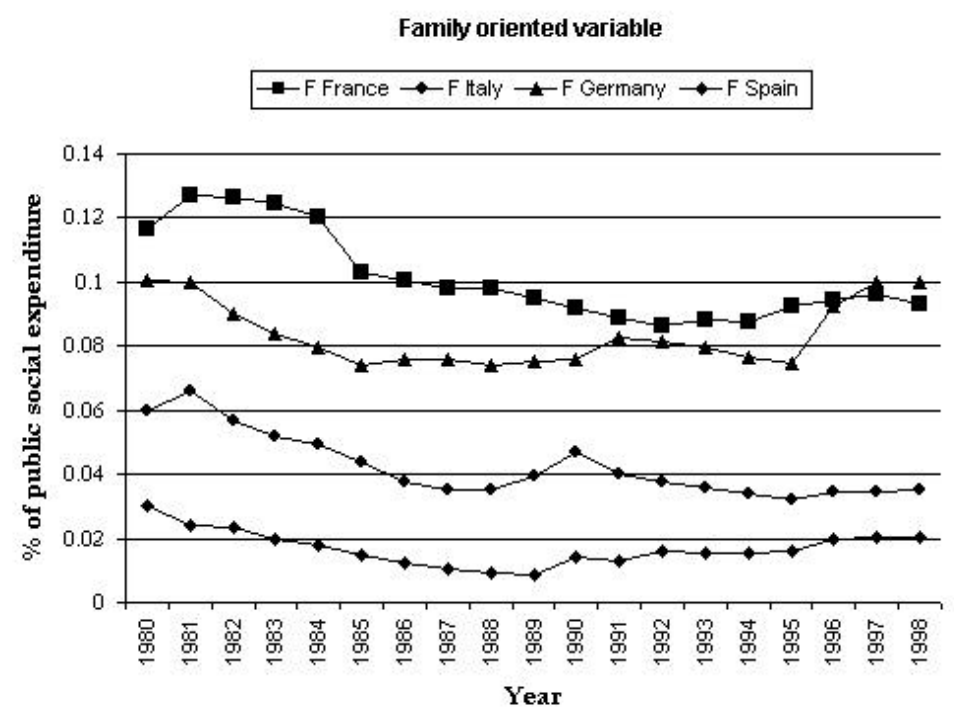

Figure 3: Percentage of socex in family programs

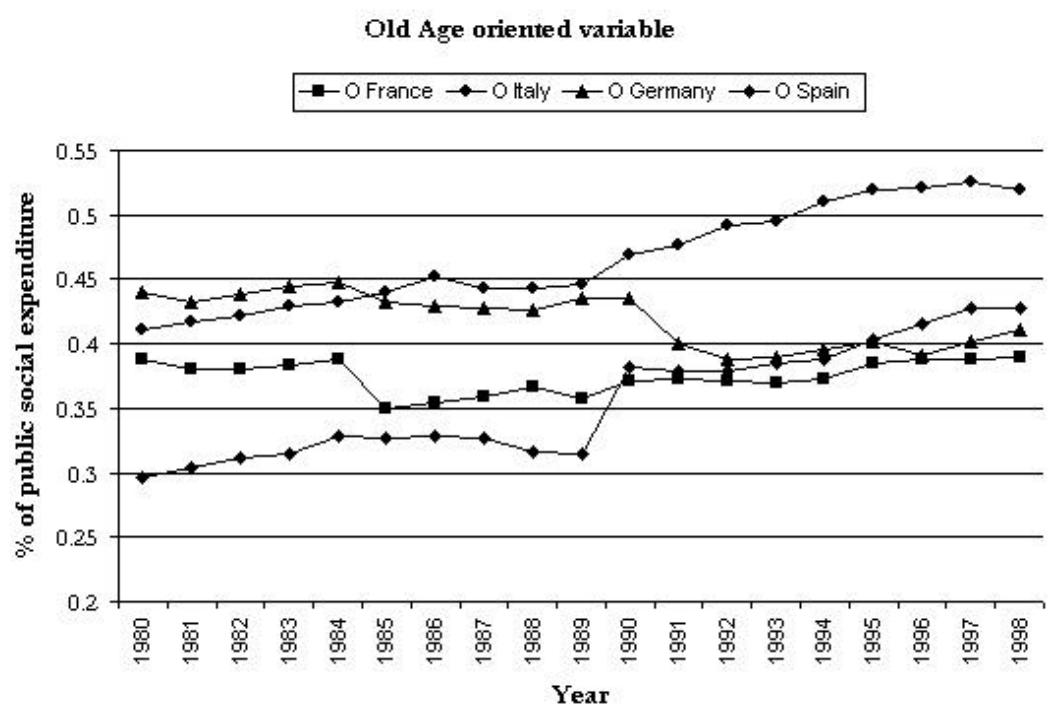

Figure 4: Percentage of socex in old age programs 
results to present the most statistically compelling arguments for harmonization. Even in this extreme scenario in favor of harmonization, the costs of implementation of an harmonization policy may still outweigh the expected benefits of harmonization.

\subsection{Structural impacts of the social expenditure on the growth rates}

The purpose of this first analysis is to extract from the data the overall picture of any impact of social expenditure on the structure of the national economies. This methodology may provide insights into which specific countries can benefit or not from harmonization policies.

The model will look at differences in changes in GDP growth between countries relative to changes in social expenditures such as spending on education, health care, and the variables available with the OECD data that the model will use. The purpose of these tests is to build on the demonstration by the previous tests that the level of social expenditure in various programs has an impact on GDP by regressing the differences in GDP growth between countries on the changes in the level of social expenditure in those countries.

We have taken different econometric approaches to analyzing the data. Modifying the variables beyond lagging them one period had little positive affect on the capabilities of the model.

Squaring the values of the variables was unsuccessful in improving even the regressions involving Italy-Germany and Italy-Spain, but lagging the natural $\log$ of the variables successfully captured the non-linear aspects of the behavior of the variables, as well as the delay between program implementation and impact on output. The direction of causality this question considers, that social expenditures impact GDP growth, is further tested by using time value minus one independent variables.

The lagged model for Italy-Germany, the first model listed, that used the natural log of the independent variables explained $62.3 \%$ of the behavior of the independent variable, an improvement in terms of significance of the linear model, with no loss in descriptive power. The behavior of the variables may be thus non-linear in some form; descriptive natural logs of variables would imply that a percentage change in social expenditure produces a unit change in GDP growth. 
Breitung's test (Breitung 2002) for non-parametric data is used to determine the presence of unit roots, and the Breusch-Pagan test is applied to test for heteroscedastic robustness. The presence of unit roots in the variables is improved by taking the natural $\log$ of each variable. $L^{1} l_{n}{ }_{x}$ denotes that that both a lag and the natural log are used; the variables in each regression may have one, both, or neither modification.

- Italy-Germany, lin-log, lagged variables ${ }^{3}$

$$
\begin{aligned}
G D P_{I D}^{\prime}= & 10.01-9.005 L^{1} \ln \quad H+10.596 L^{1} \ln \quad O A \\
& -16.136 L^{1} \ln \quad{ }_{D}+\epsilon, \bar{R}^{2}=.6899
\end{aligned}
$$

- France-Germany, linear, lagged variables

$$
\begin{gathered}
G D P_{F D}^{\prime}=-3.135-52.89 L^{1} \ln \quad{ }_{U}+109.76 L^{1} \ln \quad O \\
-144.28 L^{1} \ln \quad{ }_{F}+87.59{ }_{D}+\epsilon, \bar{R}^{2}=.2803
\end{gathered}
$$

- France-Italy, linear, lagged variables

$$
\begin{aligned}
G D P_{F I}^{\prime}= & -0.941-21.92 L^{1} \ln \quad H+15.92 L^{1} \ln \quad O A \\
& -53.92 L^{1} \ln \quad{ }_{D}+\epsilon, \bar{R}^{2}=.5332
\end{aligned}
$$

- France-Spain, linear

$$
G D P_{F E}^{\prime}=-0.742+8.91 \quad O A+\epsilon, \bar{R}^{2}=.082
$$

- Italy-Spain, linear, lagged variables

$$
\begin{gathered}
G D P_{I E}^{\prime}=-.370-93.547 L^{1} \quad U-90.004 L^{1} H \\
-84.089 L^{1} \quad O A-63.56{ }_{D}+\epsilon, \bar{R}^{2}=.5821
\end{gathered}
$$

- Germany-Spain, linear, lagged variables

$$
\begin{gathered}
G D P_{F D}^{\prime}=10.768+1.064 L^{1} \quad U-57.588 L^{1} H \\
-46.533 L^{1} \quad O A+104.227 \quad D+\epsilon, \bar{R}^{2}=.5631
\end{gathered}
$$

\footnotetext{
${ }^{3}$ See appendix 1 for further details.
} 
The results presented are the most descriptive ones, whether linear or otherwise, that are heteroscedastistically robust, and those that would lend the most support to harmonization.

The coefficients of the Italy-Germany regression are anticipated, as this model represents purely structural effects. Unemployment benefits generally have a negative impact on GDP, as do disability benefits, but raising the lifetime consumption function of the elderly increases output. The results here are heteroscedastistically robust, and the presence of unit roots has been diminished in some cases where necessary by taking the natural logarithm of each independent variable. ANOVA tests did not reveal multicollinearity or covariance.

\subsection{Dynamic impacts of the social expenditure on the growth rates}

Changes in social expenditure as a percentage of GDP from year to year reflects policy change. Policy differences between two countries may impact their output, causing their levels of growth to diverge. One of those first two countries, and another, a third country may also have divergent growth levels, but at a rate different still from that between the first two countries. Asymmetric shocks due to discrepancies in social expenditures between countries may exist.

\subsubsection{Impacts of individual programs on differences in growth rates between countries}

To investigate this possibility, the change in GDP is regressed on the change in the level of social expenditure at the program level as a fraction of GDP. The changes in program size as a percentage of GDP are examined for France, Germany, Italy, and Spain, and then the differences in program and output growth are examined between each country. Variables, e.g. $\Phi_{U}$ for unemployment, are derived:

$$
\Phi_{U_{F}}=\left(U_{F_{1997}} / G D P_{F_{1997}}\right) /\left(U_{F_{1996}} / G D P_{F_{1996}}\right)
$$

The equation takes the following form:

$$
G D P^{\prime}=\beta_{0}+\beta_{1} \Phi_{a}+\beta_{2} \Phi_{b}+\beta_{3} \Phi_{c}+\epsilon
$$


Where $\Phi$ is the percentage change in program expenditure as a percentage of GDP from the previous year. Each $\beta$ represents a different program variable.

\subsubsection{Impacts of combined program variables on differences in growth rates between countries}

Analyzing the impact of policy changes on GDP growth within a particular country showed that policy changes in a given year or the previous year did not have a consistent impact on GDP growth. These regressions reflect the priority accorded given programs by measuring the relationship between change in expenditures as a percentage of GDP and GDP growth. While interesting to note that policy changes do not appear to affect output growth nationally, international relationships will shed light on harmonization possibilities.

France, Italy, and Spain all produce significant results when their policy changes' impact on GDP is compared with Germany. When comparing two countries $a$ and $b$, the variable $\Phi_{a b}$ is derived by taking the difference in values for each country for a particular year:

$$
\Phi_{a b_{1997}}=\Phi_{a 1997}-\Phi_{b_{1997}}
$$

These differences between Germany and the other countries produce descriptive models. Attempts to capture possible non-linear effects by squaring the independent variables were chronically heteroscedastic in the error terms and devoid of statistically significant independent variables. All six combinations of the four countries chosen were examined for different combinations of variables.

In order to correct for the presence of a unit root in the data strings, due to the model's non-parametric nature, the natural logs of each independent variable was used where testing revealed this eliminated the unit root problem. Breitung's non-parametric test (Breitung 2002) was again used to test for the presence of unit roots in the independent variables.

In the analysis between Italy and Germany of the dynamic policy effects analyzed by this model, taking the natural logs of the independent variables, $69.8 \%$ of the behavior of the dependent variable was explained by the model. The model was significant overall and heteroscedastistically robust.

Following the Italy-Germany model are the most robust, most descriptive results for each other country combination. 
- Italy-Germany, lin- $\log ^{4}$

$$
\begin{gathered}
G D P_{I D}^{\prime}=.296+4.637 \ln \Phi_{U}-38.813 \ln \Phi_{O} \\
+19.621 \ln \Phi_{D}+\epsilon, \bar{R}^{2}=.6978
\end{gathered}
$$

- France-Germany, linear

$$
\begin{gathered}
G D P_{D E}^{\prime}=.287+1.228 \Phi_{U}-38.813 \ln \Phi_{O} \\
+19.621 \ln \Phi_{D}+\epsilon, \bar{R}^{2}=.3419
\end{gathered}
$$

- France-Italy, linear

$$
\begin{gathered}
G D P_{F I}^{\prime}=.197+1.366 \Phi_{U}-11.828 \Phi_{O A} \\
-7.470 \Phi_{D}+\epsilon, \bar{R}^{2}=.6093
\end{gathered}
$$

- France-Spain, linear, lagged variables

$$
G D P_{F E}^{\prime}=-.767-.156 \Phi_{O A}+\epsilon, \bar{R}^{2}=-0.067
$$

- Italy-Spain, linear, lagged variables

$$
\begin{aligned}
& G D P_{I E}^{\prime}=-.656+3.908 L^{1} \Phi_{U}-3.070 L^{1} \Phi_{H} \\
& -10.521 L^{1} \Phi_{O A}-2.5356 \Phi_{D}+\epsilon, \bar{R}^{2}=.0406
\end{aligned}
$$

- Germany-Spain, linear, lagged variables

$$
G D P_{D E}^{\prime}=-.0685+11.594 \Phi_{U}-13.594{ }_{O A}+\epsilon, \bar{R}^{2}=.3240
$$

All results are heteroscedastistically robust and have been tested for the presence of a unit roots. Variables where a unit root is present are replaced with the natural $\log$ of the variable when that improves the unit root test. In the cases where taking the natural log does not help, the unit root is likely due to the small size of the data set.

Multicollinearity has not been observed. The heterogeneity of the following results suggests that policy changes would have variable impacts on output, adding further uncertainty to harmonization considerations.

\footnotetext{
${ }^{4}$ See appendix 2 for further details.
} 
The signs of the coefficients of the Italy-Germany model here are somewhat different from those found in the structural regression, with the Old age oriented variable having a negative coefficient while Unemployment and the Disability oriented variable both have positive coefficients. This may reflect the impact of changing policy, as opposed to the level (like in the structural regression), decreasing the importance of factors such as the opportunity cost of not working. This regression takes into account not only macroeconomic conditions but the affects of uncoordinated international policy.

Based on these regressions, we can conclude that there are at least significant differences in the relationships between countries. Differences between countries' growth rates can be explained by social expenditure sometimes, but the inconsistent signs of the coefficients show that the differences are not uniform. The irregularities of these dynamic effects will be addressed with the policy implications.

\section{$5 \quad$ Policy implications}

The policy implications may be twofold. First, the analysis focused on explaining changes in GDP by changes in the amount of specific components of social expenditure within a given country. Changes in GDP are determined by many different variables, from wage levels, to firm profits, to regulations. We can demonstrate that changes in GDP are also related to changes in social expenditure. Being a part of the EMU, which may become more like an OCA, the member countries may be interested in harmonizing particularly those expenditure levels which have an impact on output fluctuations. Second, knowing that social expenditure in the individual countries can explain changes in GDP, the next step was to explain the impact of changes in social expenditure programs on differences in GDP growth levels between countries. We have measured two effects, one structural and one dynamic. The structural effect captures the weight of the component programs in total social expenditure. With the dynamic effect we capture the impact of changes in the cost of each social expenditure component.

On the one hand the econometric results demonstrate that there is a relationship between the amount of program expenditure and changes in GDP between countries. The differences in the weight of individual social programs between major countries in Europe explains differences in GDP growth. However, the differences in GDP growth between major countries 
are not uniform. On the other hand, at once with econometric robustness and macroeconomic relevancy we measure the existence of any dynamic effect. Changes in social expenditure policy are reflected in the econometrics by the weight of component programs as a percentage of GDP. The relationship between changes in this weight and changes in GDP growth has been confirmed, underscoring the impact of social expenditure policy changes on output growth. Here the changes in program policy were measured rather than the weight of each program. Based on the result that differences in social expenditure have an impact on GDP there may be a Pareto-optimal level of social expenditure in Europe that can reduce discrepancies in GDP growth.

We elucidated at once a structural effect and a dynamic effect, showing that while harmonization may be beneficial to smooth differences in GDP growth, harmonization must take into account the weight of each individual program in the different countries. By doing so, the harmonization will lead to a convergence of GDP. The Pareto-optimum solution is harmonization that eliminates the idiosyncratic output shocks which stemmed from different social expenditure levels. The heterogeneity of the results obtained from the 'structural' regressions demonstrate that harmonization on a European level would be at least difficult. But we also observe a dynamic effect, the changes in policy themselves, which creates additional discrepancies in GDP growth. Europe may consider that the Pareto-optimum situation is represented by no discrepancies in GDP growth, but policy change will amplify differences in growth trends.

Determination of an optimal expenditure level requires countries to converge, and when countries change their policies to meet this level output growth will diverge. The likelihood that this dynamic effect is larger than the gains represented by structural harmonization is high. This result may confirm on the social policy side that harmonization will not bring convergence. As Krugman (Krugman 1993) forecast for the economies of the EMU, harmonization of economic policy will lead to the amplification of regional comparative advantage; in other words, divergence.

Nevertheless, these results do not advocate in favor of cooperation to the expenses of harmonization, but a third-way could be found: the "open coordination" notion used in Luxembourg. Indeed, the policymakers could be inspired by the Stability and Growth Pact and propose a harmonized pricefloor (Scharpf 1997) for welfare spending in each country (the current average is close to $25 \%$ of the GDP spent on welfare programs) leaving the freedom 
to allocate the resources on each program fitting with the country's culture. It would help create the incentive to converge without imposing strict procedures and facing the paradoxical outcome of harmonization: divergence.

\section{Conclusion}

This paper sought to provide at once an original measurement of the welfare state by considering levels of social expenditure and its relationship to GDP to further the discussion of the implications of harmonizing European welfare policies.

Optimum currency area theory suggests that certain regions should take advantage of a common currency. With the creation of the Economic and Monetary Union, Europe began monetary policy harmonization. The Stability and Growth Pact, limiting the public deficit to three percent of GDP is a rule that places a restriction, albeit nonspecific, on fiscal policy.

With a common monetary policy and a fiscal policy rule in place EMU member countries have little recourse for unilateral maneuver when stimulation or cooling becomes necessary. What remains for countries to do on their own is to determine the level of public expenditure. The level of various public expenditures and the structure of programs designed to uphold welfare where the free market might not have an interest is determined on a country level.

This paper did not discover evidence to support policy harmonization on the European level for welfare programs - representing a big share of the budget expenditure. Asymmetric output shocks exist, but are different depending on the set of countries. Harmonization between countries that do not display a relationship between social policy and growth trends could be harmful and amplify swings in output growth. During the years following harmonization the side effects may be greater than the benefits.

\section{References}

Alesina, A. and R. Perroti (1997). The welfare state and competitiveness. American Economic Review 87(5), 921-939.

Barr, N. (1992). Economic theory and the welfare state: A survey and interpretation. Journal of Economic Literature 30 (2), 741-803. 
Breitung, J. (2002). Nonparametric tests for unit roots and cointegration. Journal of Econometrics 108, 343-364.

Delors, J. (1989). Economic and monetary union and relaunching the construction of europe. In C. of the Study of Economic and M. Union (Eds.), Report on Economic and Monetary Union in the European Community. Luxembourg: Office of Official Publications of the European Communities.

Hitiris, T. (1997). Health care expenditure and integration in the countries of the european union. Applied Economics 29, 1-6.

Hitiris, T. and J. Nixon (2001). Convergence of health care expenditure in the eu countries. Applied Economics Letters 8(4), 223-228.

Holmlund, B. and A. Kolm (2000). International spillover effects of sectoral tax differentiation in unionized economies. Cesifo Working Papers Series 295.

Johnson, H. (1968). The economic approach to social questions. Economica 35(137), 1-21.

Krugman, P. (1993). Integration, specializatin and regional growth: Notes on 1992. In F. Torres and F. Giavazzi (Eds.), Adjustment and growth in the European Monetary Union. Cambridge: Cambridge University Press.

Mosher, J. (2000, Summer). Open method of coordination: Functional and political origins. ECSA Review 13 (3).

Perotti, R. (1996). Fiscal consolidation in europe: Composition matters. American Economic Review 86(2), 105-110.

Rodhes, M. (2000, Summer). Lisbon: Europe's "maastricht for welfare?". ECSA Review.

Scharpf, F. (1997). Konsequenzen der globalisierung fuer di nationale politik. International Politik und Gesellchaft 2, 184-192.

Slesnick, D. (1998). Empirical approaches to the measurement of welfare. Journal of Economic Literature 36(4), 2108-2165. 


\section{Appendix 1}

\begin{tabular}{|c|c|c|c|c|c|c|}
\hline \multirow[t]{3}{*}{ Structural } & \multicolumn{6}{|c|}{ (results for the most staistically descriptive regression) } \\
\hline & \multicolumn{6}{|c|}{$\begin{array}{l}\mathrm{L}=\text { denctes variable lagged } 1 \text { year } \\
\mathrm{I}=\text { denotes natural log of variable }\end{array}$} \\
\hline & $\mathrm{U}$ & $\mathrm{H}$ & OA & $\mathrm{F}$ & $\mathrm{O}$ & $\mathrm{D}$ \\
\hline France - Gemany & $\mathrm{L}$ & & & $\mathrm{L}$ & $\mathrm{L}$ & $\mathrm{L}$ \\
\hline coefficient & 52.894 & & & 144.282 & 109.756 & 87.59 \\
\hline t-ratio (13df) & 2.58 & & & 2.987 & 2.487 & 1.543 \\
\hline p-value & 0.01 & & & 0.003 & 0.0123 & 0.123 \\
\hline \multicolumn{7}{|l|}{ adj. R-square $=.2803$} \\
\hline France - Italy & & $\mathrm{L}$ & $\mathrm{L}$ & & & $\mathrm{L}$ \\
\hline coefficient & & -21.926 & 15.92 & & & -53.92 \\
\hline t-ratio (14df) & & -2.315 & 0.9327 & & & -2.316 \\
\hline$p$-value & & 0.036 & 0.367 & & & 0.036 \\
\hline \multicolumn{7}{|l|}{ adj. R-square $=.5332$} \\
\hline \multicolumn{7}{|l|}{ France - Spain } \\
\hline coefficient & & & 8.9123 & & & \\
\hline t-ratio (17df) & & & 1.615 & & & \\
\hline $\mathrm{p}$-value & & & 0.125 & & & \\
\hline \multicolumn{7}{|l|}{ adj. R-square= .082} \\
\hline Italy - Germany & & $\mathrm{L}, \mathrm{ln}$ & $L_{1} \ln$ & & & L, In \\
\hline coefficient & & -9.005 & 10.596 & & & -16.138 \\
\hline t-ratio (14 df) & & -4.976 & 5.087 & & & -5.516 \\
\hline p-value & & 0 & 0 & & & 0 \\
\hline \multicolumn{7}{|l|}{ adj. R-square $=.6899$} \\
\hline Italy - Spain & $\mathrm{L}$ & L & L & & & $\mathrm{L}$ \\
\hline coefficient & -93.537 & -90.004 & -84.089 & & & -63.56 \\
\hline t-ratio (13df) & -3.808 & -3.407 & -3.304 & & & -4.418 \\
\hline p-value & 0.002 & 0.005 & 0.006 & & & 0.001 \\
\hline \multicolumn{7}{|l|}{ adj. R-square $=0.5821$} \\
\hline Gexmany - Spain & $\mathrm{L}$ & $\mathrm{L}$ & $\mathrm{L}$ & & & $\mathrm{L}$ \\
\hline coefficient & 1.0643 & -57.788 & 46.533 & & & 104.23 \\
\hline t-ratio (13df) & 0.05818 & -4.328 & 4.906 & & & 3.976 \\
\hline p-value & 0.954 & 0.001 & 0 & & & 0.002 \\
\hline adj. R-square= .5631 & & & & & & \\
\hline
\end{tabular}




\section{Appendix 2}

\begin{tabular}{|c|c|c|c|c|c|c|}
\hline \multirow[t]{2}{*}{ Dynamic } & \multicolumn{6}{|c|}{$\begin{array}{l}\text { (results for the most staistically descriptive regression) } \\
L=\text { dendtes variable lagged } 1 \text { year } \\
\text { In= denotes natura log of variable }\end{array}$} \\
\hline & U & $\mathrm{H}$ & $O A$ & $\mathrm{~F}$ & 0 & D \\
\hline \multicolumn{7}{|l|}{ France - Gem any } \\
\hline coefficient & 1.22763 & & & 7.67773 & -18.93527 & \\
\hline t-ratio (14 df) & 2.627 & & & 2.69 & -2.068 & \\
\hline $\begin{array}{c}\text { p-value } \\
\text { adj. R-square }=3419\end{array}$ & 0.0086 & & & 0.03865 & 0.39458 & \\
\hline \multicolumn{7}{|l|}{ France - Italy } \\
\hline coefficient & 1.3662 & & -11.828 & & & 7.4695 \\
\hline t-ratio (14df) & 4.977 & & -2.749 & & & 2.219 \\
\hline p-value & 0 & & 0.016 & & & 0.044 \\
\hline \multicolumn{7}{|l|}{ adj. R-square= .6903} \\
\hline France - Spain & & & $\mathrm{L}$ & & & \\
\hline coefficient & & & -0.15587 & & & \\
\hline t-ratio (15df) & & & -0.02953 & & & \\
\hline$p$-value & & & 0.977 & & & \\
\hline \multicolumn{7}{|l|}{ adj. R-square $=-.066$} \\
\hline Italy - Germany & $\ln$ & & & & In & In \\
\hline coefficient & 4.63687 & & & & -38.81339 & 19.62075 \\
\hline $\begin{array}{c}\text { t-ratio }(14 \mathrm{df}) \\
\text { p-value }\end{array}$ & $\begin{array}{c}4.231 \\
0\end{array}$ & & & & $\begin{array}{c}-5.607 \\
0\end{array}$ & $\begin{array}{c}4.278 \\
0\end{array}$ \\
\hline \multicolumn{7}{|l|}{ adj. R-square $=.6978$} \\
\hline Italy - Spain & $\mathrm{L}$ & $\mathrm{L}$ & $\mathrm{L}$ & & & $\mathrm{L}$ \\
\hline coefficient & 3.9075 & -3.0702 & -10.521 & & & -2.5356 \\
\hline t-ratio (12df) & 1.734 & -0.4014 & -1.005 & & & -0.5562 \\
\hline $\mathrm{p}$-value & 0.109 & 0.695 & 0.335 & & & 0.588 \\
\hline \multicolumn{7}{|l|}{ adj. R-square $=0.0406$} \\
\hline \multicolumn{7}{|l|}{ Germany - Spain } \\
\hline coefficient & & 11.594 & -13.594 & & & \\
\hline t-ratio (15df) & & 2.304 & -2.794 & & & \\
\hline p-value & & 0.036 & 0.014 & & & \\
\hline adj. R-square= .3240 & & & & & & \\
\hline
\end{tabular}

